\title{
La figura del directivo público profesional: reclutamiento y estatuto
}

\author{
Carmen Blanco Gaztañaga \\ Administradora del Estado \\ cblancogaz@mtin.es
}

\begin{abstract}
Resumen
Este artículo se centra en la función directiva profesional, el interfaz existente entre la esfera política y la administración pública. La configuración de la función directiva profesional en cada país de la OCDE es consecuencia de su sistema constitucional y administrativo y depende de las relaciones entre política y Administración. Los pilares del estatuto del directivo público son la selección de los directivos, el sistema de remuneraciones y el cese.
\end{abstract}

Palabras clave Función directiva profesional, selección, apertura de puestos a no funcionarios, retribuciones por desempeño, cese, injerencia política.

\section{The Senior Civil Service: recruitment and status}

\begin{abstract}
This article focus on Senior Civil Service (SCS), the interface between the political government and the public administration. The SCS arrangements across OECD countries is a consequence of his constitutional and administrative system and depends on the relationships between politics and Administration. The key elements of SCS arrangements are the recruitment process, the remuneration system and dismissals.
\end{abstract}

Key words

Professional leadership roles, selection, open jobs for no government employees, unemployment compensations, cessation, political interference. 
"We aim to provide high-quality advice and support to the Government and help deliver world-class public services, while consistently applying our core values of honesty, objectivity, integrity and impartiality."

\author{
Sir Gus O'Donnell \\ Head of the Home Civil Service'
}

Monsieur le Président:

Une fonction publique de carrière structurée autour des valeurs du service de l'intérêt général est un bien collectif ainsi qu'un élément de l'identité et de la cohesión de la France.

Monsieur Jean Ludovic SILICANI2

Conseiller d'Etat

\title{
1. INTRODUCCIÓN
}

Dentro de los distintos procesos de reforma de las Administraciones Públicas uno de los elementos más importantes es la definición y regulación del directivo público profesional.

En los últimos años han sido numerosos los países que han creado una estrato profesional en el vértice de la Administración que sirva de vínculo entre el poder político y la Administración, esto es lo que se viene denominando Senior Civil Service y que, en este artículo, utilizando la terminología del Estatuto del Empleado Público, denominaremos función directiva profesional o directivo público.

La definición y la amplitud de la función directiva, la selección de sus miembros y su estatuto han sido y continúan siendo objeto de un amplio debate. Las soluciones que se han adoptado en los diferentes países están en gran medida vinculadas a su tradición histórica y constitucional y al sistema de relaciones entre la Administración y el Gobierno.

\section{EL DIRECTIVO PÚBLICO PROFESIONAL}

Hay tres vértices que dibujan la figura del directivo público: profesionalidad, garantías de imparcialidad y relaciones con el poder político. Esto se debe a que los ob-

1 Nosotros queremos proporcionar al Gobierno asesoramiento de alto nivel y apoyo y ayudarle a prestar servicios públicos de categoría mundial, mientras aplicamos coherentemente nuestros valores fundamentales de honestidad, objetividad, integridad e imparcialidad.

2 Señor Presidente:

Una función pública de carrera estructurada en torno a los valores de servicio al interés general es un 180 bien colectivo a la vez que un elemento de la identidad y de la cohesión de Francia. 
jetivos de toda función directiva profesional son que los puestos directivos en la Administración estén ocupados por "los mejores y más brillantes" y que además se logre el equilibrio entre la imprescindible imparcialidad en la actuación de la Administración y la responsabilidad de los cargos electos ante la ciudadanía por el cumplimiento del programa de Gobierno.

En el siguiente dibujo se contienen los tres vértices del directivo público:

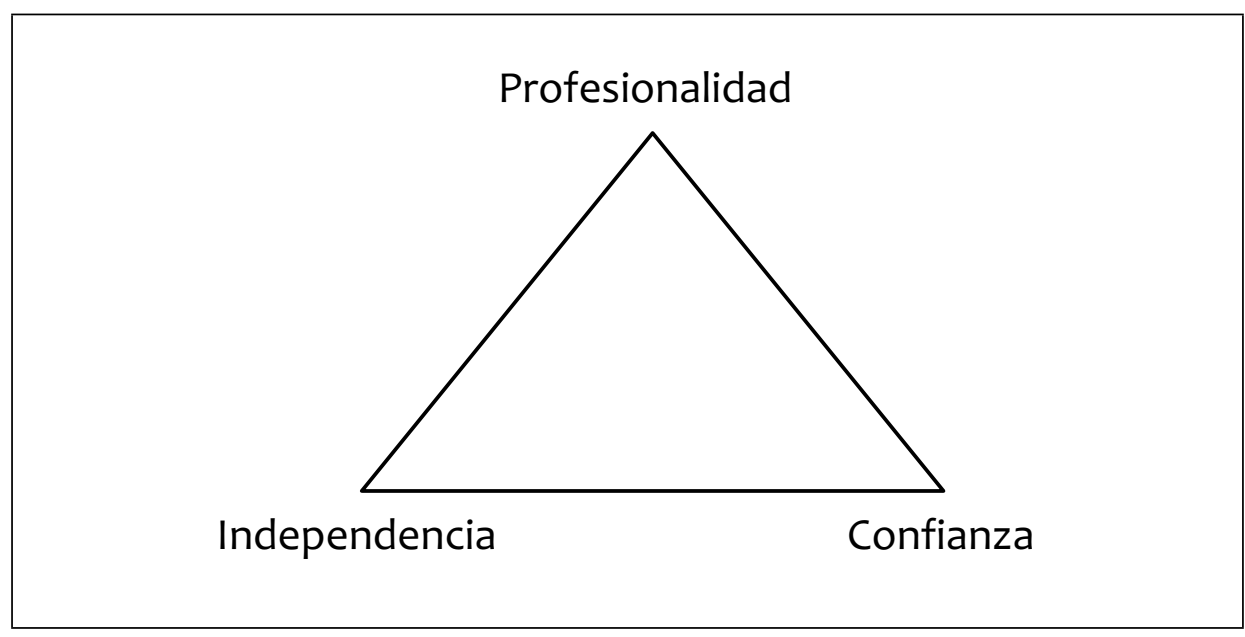

En algunos países se ha creado una función directiva profesional estructurada, como el Senior Civil Service inglés o la dirigenza italiana, diferenciada del resto del empleo público. En otros países, no existe una formalización tan clara de la función directiva. La OCDE elaboró un estudio en 2006 para determinar el grado de estructuración de la función directiva pública en los diferentes países. Para la calificación de los sistemas se tuvieron en cuenta los siguientes indicadores:

- Existencia dentro de la Administración de un colectivo directivo profesional diferenciado.

- Los mecanismos formales o informales para la selección de los directivos públicos y la determinación previa de las competencias requeridas.

- La edad media de acceso a la función directiva

- Estatuto normativo propio.

De acuerdo con dichos parámetros se elaboró la siguiente tabla. En ella, España aparece en último lugar, si bien hay que tener en cuenta que en 2006 no se había aprobado todavía la Ley 7/2007 del Estatuto del Empleado Público. 
TABLA 1

Grado de estructuración de la función directiva pública

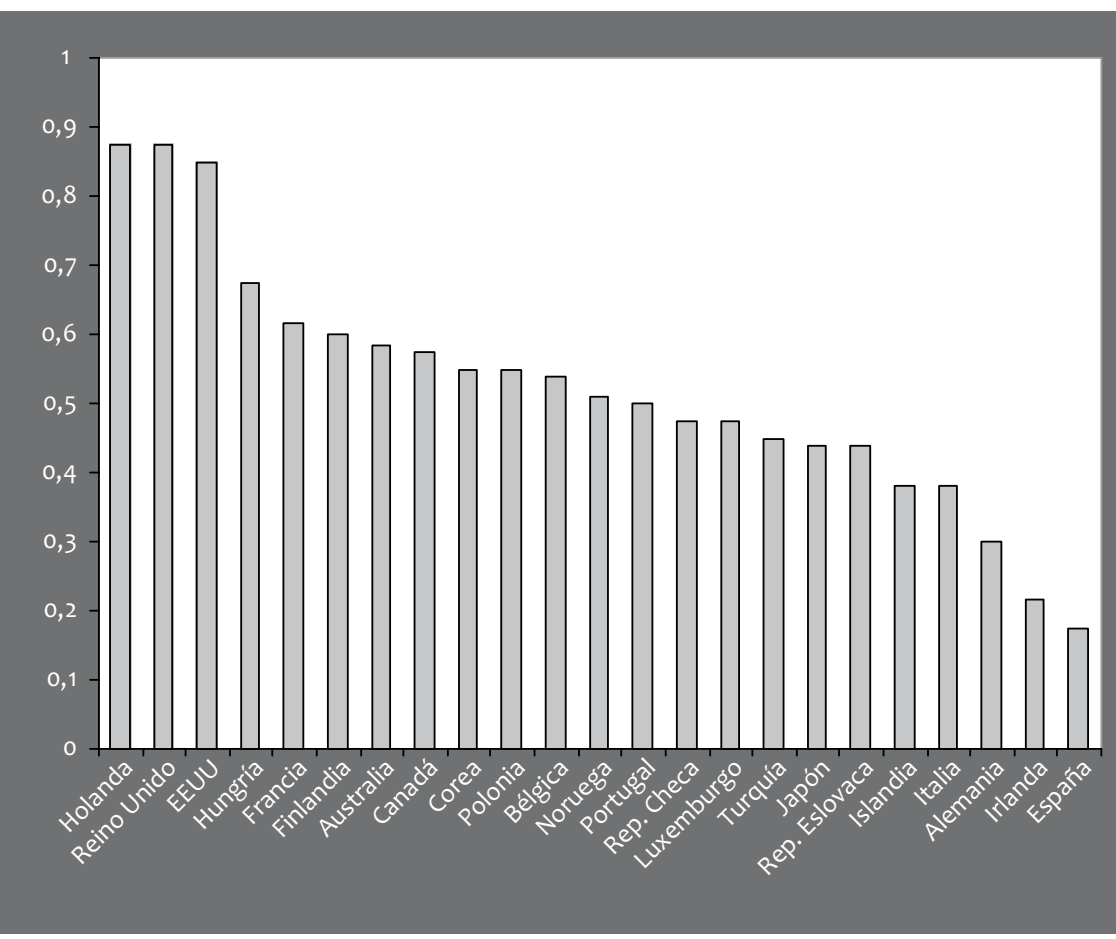

Fuente: OCDE. Survey on Strategic Human Resources Management in Government, OECD, 2006.

Por su parte el Banco Mundial, (Banco Mundial, 2005) ha definido dentro de la función directiva pública las siguientes características:

a) Conjunto de "funcionarios" nombrados en los puestos más altos de la organización.

b) Generalmente están encargados de la elaboración de las políticas o de la dirección de las Agencias.

c) Trabajan en estrecha colaboración con los Ministros y los cargos políticos.

d) Tienden a tener un perfil más generalista que especializado, pero pueden llegar a dirigir Agencias con competencias muy especializadas.

e) Suponen un pequeño porcentaje, inferior al $1 \%$, del total de funcionarios.

182 f) La selección es competitiva. 
g) Reciben una mayor formación que el resto de los funcionarios.

h) Gozan de una mejor remuneración y, en ocasiones, de mayor prestigio que el resto de los funcionarios.

i) Su carrera está vinculada al cumplimiento de objetivos.

j) Deben cumplir unas normas de conducta especiales.

Hoy, estando pendiente de desarrollo el Estatuto del Empleado Público, hay muchas cuestiones que continúan abiertas. Con ánimo de contribuir al debate, en este artículo se analizará la manera en la que se ha dado respuesta en el ámbito internacional a la problemática de la función directiva profesional y la situación actual en nuestro país.

\section{JUSTIFICACIÓN DE LA REGULACIÓN DE LA FUNCIÓN DIRECTIVA PROFESIONAL}

La OCDE (OCDE, 2008) agrupa en tres tipos las razones que existen para la creación de una función directiva profesional:

a) Clarificar la frontera entre política y administración.

b) Introducción de cierto grado de flexibilidad en la selección y en las condiciones de trabajo de los directivos públicos.

c) Creación de una cultura común.

a) Introducción de cierto grado de flexibilidad en la selección y en las condiciones de trabajo de los directivos públicos

Como es conocido, existen dos modelos distintos de Función Pública:

- El sistema cerrado o de carrera, de origen francés, en el que los funcionarios son seleccionados al inicio de su carrera mediante oposiciones para ingresar en un Cuerpo, no en un puesto concreto. Los funcionarios cuentan con una normativa específica, estatutaria, diferente del derecho laboral general.

- El sistema abierto o de puesto, más próximo al derecho laboral, en el que se selecciona para puestos concretos.

El sistema de carrera configura la función pública como un ámbito propio distinto del sector privado. El sistema de puesto, defendido desde las teorías de nueva 
gestión pública, se ajusta mejor a la lógica empresarial. Tanto en los países con sistema abierto como con sistema cerrado, uno de los objetivos prioritarios de la elaboración del estatuto del directivo es permitir una mayor flexibilidad en la determinación de sus condiciones tanto retributivas como de trabajo.

En cuanto a la selección, los aspectos más importantes son el grado de apertura de los puestos al sector privado y el sistema de garantías para asegurar la profesionalidad. La solución adoptada por cada país, como se verá más adelante, está muy entroncada con su sistema constitucional y administrativo.

Respecto de las condiciones retributivas la tendencia mayoritaria es vincularlas con el cumplimiento de objetivos, de manera que se elimine la automaticidad en una gran parte de los complementos y que se fomente la eficacia en la actuación. En este punto, se trataría de asemejar, en la medida de lo posible, la situación del directivo público con la del directivo del sector privado. No obstante, como se analizará más adelante, no resulta tan sencillo la extrapolación teniendo en cuenta lo difícilmente medibles que son los objetivos públicos.

\section{b) Clarificar la frontera entre política y administración}

Dado que el directivo público se sitúa como puente entre el ámbito político y el técnico, una de sus finalidades es de servir de nexo entre ambos campos, permitiendo que el político cuente con toda la información necesaria para poder escoger la mejor alternativa y que sea conocedor de posibles inconvenientes o dificultades que pueden surgir en la implementación de las políticas.

El grado de implicación política varía mucho de un país a otro. La OCDE elaboró un estudio sobre la participación política en la función directiva y la delimitación de responsabilidades entre Ministros y directivos públicos en varios países, que no incluían a España (OCDE, 2007). En él se analiza como sin un cierto grado de intervención política en la Administración no podrían llevarse a cabo las políticas del Gobierno. No obstante, una injerencia excesiva puede producir la utilización del aparato administrativo con fines partidistas. Además, la neutralidad permite que exista una continuidad en la actuación de la Administración con independencia de los cambios políticos.

En la tabla siguiente, aparece el grado de participación política en los nombramientos de directivos públicos. 
TABLA 2

Participación política en los nombramientos públicos

\begin{tabular}{|c|c|c|c|c|c|c|}
\hline País & Nivel 1 & Nivel 2 & Nivel 3 & Nivel 4 & Nivel 5 & Asesores \\
\hline EEUU & Político & Político & Político & $\begin{array}{l}\text { Político- } \\
\text { híbrido }\end{array}$ & $\begin{array}{l}\text { Político- } \\
\text { híbrido }\end{array}$ & Político \\
\hline Suecia & Político & Político & Político & Político & Adm. & Político \\
\hline Italia & - & - & Político & Político & Adm. & Político \\
\hline Sudáfrica & Político & Político & Híbrido & Híbrido & Adm. & - \\
\hline México & Político & Político & Adm. & Adm. & Adm. & Híbrido \\
\hline Francia & Político & Híbrido & Híbrido & Híbrido & Adm. & - \\
\hline Bélgica & Híbrido & Híbrido & Híbrido & Híbrido & Híbrido & Político \\
\hline Polonia & Político & Híbrido & Adm. & Adm. & Adm. & - \\
\hline Corea & Política & Adm. & Adm. & Adm. & Adm. & - \\
\hline $\begin{array}{l}\text { Nueva } \\
\text { Zelanda }\end{array}$ & Híbrido & Adm. & Adm. & Adm. & Adm. & Híbrido \\
\hline Dinamarca & Híbrido & Adm. & Adm. & Adm. & Adm. & - \\
\hline $\begin{array}{l}\text { Reino } \\
\text { Unido }\end{array}$ & Adm. & Adm. & Adm. & Adm. & Adm. & Político \\
\hline
\end{tabular}

Fuente: OCDE.

Híbrido se refiere a procedimientos en los que se combinan criterios de selección administrativos y consideraciones políticas.

Sistema Político-Híbrido se refiere a la coexistencia en este nivel de nombramientos políticos puros con algunos administrativos.

Existen dos modelos muy distintos: el sistema americano donde los nombramientos tienen un carácter político en su mayoría y el sistema inglés que tiene como principio esencial la garantía de la no injerencia política en los nombramientos. Entre ambos, la mayoría de los países cuentan con un sistema mixto.

No obstante, la OCDE considera que el foco no debe estar tanto en la existencia de nombramientos por órganos políticos sino en los contrapesos y controles a la actuación. Según la OCDE, en los países que cuentan con un sistema constitucional fuerte, la transparencia sirve de límite al poder. Los nombramientos cuando tienen carácter político es porque pretenden incluir una responsabilidad política en el diseño y ejecución de políticas públicas, más que por razones de clientelismo. El sistema de pesos y contrapesos propio de los países anglosajones ejerce de dique de contención ante los posibles abusos.

Así, como se observa en la tabla número 2, aunque los nombramientos en Estados Unidos tienen un carácter netamente político. Sin embargo, la fortaleza de sus instituciones, la división de poderes y la conciencia democrática son garantías para 
evitar desvíos. La cultura política americana es muy diferente de la europea en este punto. Los nombramientos tienen un carácter político pero tanto el Congreso como los medios de comunicación ejercen un control muy fuerte del Gobierno que sirve de garantía frente a cualquier abuso.

En cambio, la OCDE alerta del riesgo de que estas conductas clientelares se prodiguen en países con un sistema institucional más débil, lo que supondría, además, que los directivos públicos seleccionados carecerían del grado de competencia necesaria para cumplir con sus objetivos. Por esta razón, hay países como México que han emprendido reformas para dotar de una mayor independencia a su función pública, a través de la selección mediante el principio de mérito.

Por estos mismos motivos, en Italia hay algunos autores que muestran cierta preocupación por la situación del estatuto del directivo. El profesor Stefano Battini y Benedetto Cimino (Sáncez Morón, 2007) explican como la dirigenza fue creada para impulsar la diferenciación entre política y administración. No obstante, la laboralización del estatuto de los directivos públicos ha tenido efectos contrarios. "Si el directivo público se convierte en precario como el dirigente privado sufriría el principio de imparcialidad administrativa que en el sector privado no tiene ninguna relevancia. Este es el talón de Aquiles de la reforma italiana sobre los Directivos Públicos. El principio de privatización empuja a asimilar al directivo público y al directivo privado. Pero esa asimilación conlleva una relación de confianza entre función directiva y órganos políticos, que es precisamente lo contrario de la distinción entre política y administración, en la que la reforma parecía inspirarse." En este sentido, citan los autores, la Corte Constitucional Italiana ha establecido, que "Ia inestabilidad de la función directiva es difícilmente compatible con un sistema adecuado de garantías para el directivo, que sea idóneo para asegurar un imparcial, eficaz y eficiente desarrollo de la acción administrativa" ( $n$. 103/2007).

El resultado de la investigación de la OCDE se puede resumir en los siguientes puntos:

1. Aunque todos los países asumen como propio el principio de imparcialidad, esto no se traduce automáticamente en la existencia de un proceso "no político" de nombramientos de directivos públicos.

2. Los diferentes países cuentan con un amplio abanico de normas, convenciones y mecanismos para limitar la injerencia política que son fruto de su tradición constitucional.

3. La garantía frente al uso partidista de la Administración se basa con frecuencia en un conjunto de prácticas y convenciones informales y no únicamente en normas escritas. La OCDE destaca la importancia de estas prácticas como contrapeso al poder. Los límites a la intervención política varían dependien186 do del sistema constitucional y administrativo. 


\section{c) Creación de una cultura común}

Actualmente, en los países con una sistema de función pública abierto o de puesto, se quiere dotar a la función directiva de una cultura común que no existe a través de la movilidad interdepartamental, de manera que creen unos mismos valores entre directivos de muy diferentes procedencias y que favorezca que los directivos tengan una visión de conjunto.

En países como Francia o España, con un sistema cerrado de función pública, en el que los funcionarios, al inicio de su carrera, son seleccionados a través de oposiciones para Cuerpos y no para puestos concretos, ya existe esta cultura administrativa y unos valores comunes. De hecho, la OCDE ha señalado este elemento como uno de los aspectos más positivos del sistema cerrado (OCDE, 2004).

\section{LA SELECCIÓN DEL DIRECTIVO PÚBLICO}

Cada país ha adoptado unas respuestas propias, marcadas por su propio sistema político y administrativo. Como se ha dicho, en los países con un sistema de puestos, se selecciona a los directivos públicos para puestos concretos entre funcionarios y personal procedente del sector privado. En los sistemas de carrera, se presta especial énfasis a la existencia de una cultura común y de unos mismos valores públicos. Por ello, estos países tienden a nombrar a sus directivos públicos entre los altos funcionarios que previamente han sido seleccionados a través de un sistema de oposiciones. La propia carrera administrativa actúa como vía de formación. La apertura de puestos a personal procedente del sector privado es excepcional.

Del análisis de dos modelos aparentemente opuestos, el sistema inglés y el sistema francés, se pueden observar la existencia de una cierta convergencia y de una misma preocupación: cómo garantizar la selección de los mejores y cómo garantizar la transparencia del proceso.

En los últimos 30 años la Administración inglesa ha experimentado un cambio sustancial. El sistema tradicional de Civil Service, que tenía sus raíces en el Northcote Trevelyan Report de 1853, fue puesto en cuarentena y modificado sustancialmente, al hilo de las nuevas políticas de Management. Actualmente, el Reino Unido cuenta con un sistema de función pública abierto pero, simultáneamente, un sistema de nombramientos no político. El sistema inglés tiene como objetivo claro que los nombramientos en el Senior Civil Service (SCS) se produzcan de manera neutral e imparcial. The Commissioner for Public Appointments es un organismo independiente del Gobierno cuya finalidad es garantizar que los procesos de selección son "fair", justos, y que se realizan en base al principio de mérito.

En los últimos años, el número de directivos procedentes del sector privado se ha incrementado notablemente. No obstante, esta tendencia está empezando a ser 
cuestionada. Tanto el Informe del Steering Group sobre "Senior Civil Service y estrategia de remuneración" (2008), como el Informe del Parlamento sobre Contrataciones externas en el SCS (Parlamento, 2010) alertan sobre los efectos negativos que están teniendo el elevado número de contrataciones externas:

En primer lugar, existe una diferencia retributiva notable entre los directivos funcionarios y los directivos procedentes del sector privado. En el caso de los directores procedentes del sector privado cobran un $22 \%$ más que los procedentes del Civil Service. Esta diferencia llega hasta un 28 \% en el caso de los Directores Generales.

TABLA 3

Salarios Medios de los Directivos Públicos Funcionarios y Externos

\begin{tabular}{|l|c|c|}
\hline & FUNCIONARIOS & EXTERNOS \\
\hline Deputy director & 71.000 L.E & $80.000 \mathrm{L.E}$ \\
\hline Deputy director $\left(1^{\mathrm{a}}\right)$ & 84.000 L.E. & $90.000 \mathrm{L.E}$ \\
\hline Director & 96.000 L.E. & $117.000 \mathrm{L.E}$ \\
\hline Director General & 129.000 L.E. & $165.000 \mathrm{L.E}$ \\
\hline
\end{tabular}

Fuente: Normington Report y External Appointments and SCS, Public Administration Committee, House of Commons.

Esto se debe a que existe la idea de que para atraer a personal cualificado del sector privado debe competirse con salarios más atractivos. Sin embargo, el Parlamento en su informe considera que esta diferencia retributiva no se traduce en una mayor productividad del personal externo que la justifique. Además, la investigación efectuada por el Parlamento muestra que los directivos procedentes del sector privado tienen una menor identificación con la Administración y con el servicio público que los funcionarios, una mayor tasa de rotación que los funcionarios y, en ocasiones, no acaban de encajar en el funcionamiento de la Administración. Por ello, aún manteniendo la posibilidad de contrataciones de directivos procedentes del sector privado, el Parlamento aconseja que el número no sea tan elevado como en la actualidad y que se refuerce la formación de los funcionarios para desarrollar el talento interno y reducir el número de directivos procedentes del sector privado.

En Francia, el general De Gaulle creó la Escuela Nacional de Administración tras la Segunda Guerra Mundial. Desde entonces, la ENA es la fuente principal de directivos públicos y de dirigentes políticos. Es una única Escuela en la que se seleccionan a través de una pruebas competitivas a los "altos funcionarios del Estado" que reciben una formación común y que, tras dicha formación común, son nombrados en los distintos Cuerpos.

En Francia se diferencia entre "encadrement supériur”, cuadros superiores, que incluye a los cuerpos procedentes de la ENA (administradores civiles, consejeros de 188 estado, cuerpos de inspección...) y de la Escuela Politécnica (ingenieros de minas, de 
puentes... ) y "cadres dirigeants", cargos políticos que son nombrados por Decreto del Presidente de la República y cuyo cese es discrecional.

En la tabla siguiente se observa la procedencia de los "cadres dirigeants". La situación actual muestra que la mitad de los directivos públicos proceden de la ENA, un $25 \%$ de las escuelas politécnicas, un $15 \%$ de otra función pública (profesores universitarios... ) y un $10 \%$ personal del exterior.

TABLA 4

Cuadros directivos

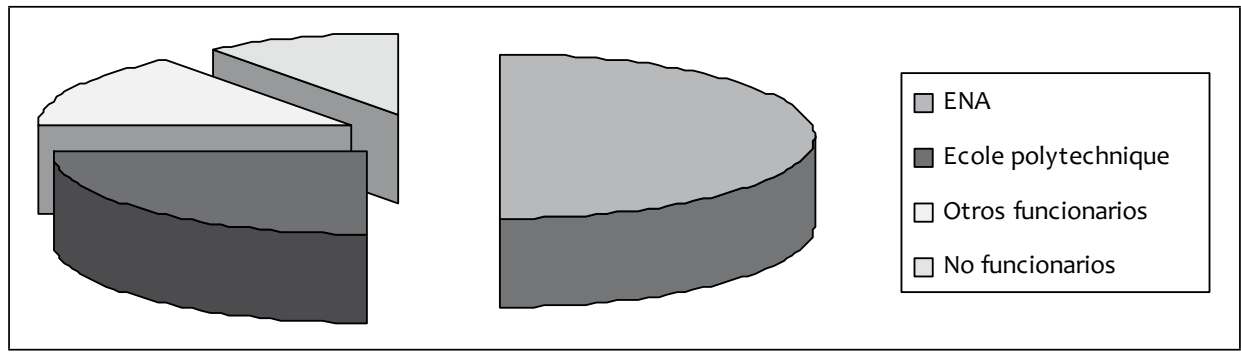

Fuente: Direction Générale de l'administration et de la fonction publique. Rep. Française

Esta composición de la función directiva francesa favorece la existencia de una fuerte cultura común y de unos valores compartidos. Por otro lado, la formación de la E.N.A. garantiza la profesionalidad de los altos funcionarios. No obstante, actualmente hay corrientes que critican este sistema por considerarlo elitista. Al hilo de la influencia de las nuevas políticas de gestión pública este sistema está siendo cuestionado. Así en Libro Blanco sobre el Futuro de la Función Pública Francesa, que en 2007 presentó el Consejero de Estado Silicani se propone que se redefina la apertura de puestos al sector privado y modificar el sistema de acceso, pero, en ese mismo estudio se constata la dificultad de llevarlo a la práctica pues el sistema de oposiciones está generalmente muy bien aceptado por la sociedad francesa por ser una garantía de imparcialidad y de igualdad.

En los distintos países de la OCDE se pueden observar las siguientes tendencias generales:

1. Una fuerte presión para la apertura de puestos al sector privado. Esta tendencia no está, en absoluto, carente de críticas por el riesgo de que se produzca una mayor politización de la Administración y una pérdida de los valores públicos, riesgo del que ha alertado la propia OCDE.

2. Un incremento de la transparencia en los procesos selectivos para garantizar la profesionalidad y evitar el clientelismo, en ocasiones encargando la selección a organismos independientes. 


\section{RETRIBUCIONES}

Las retribuciones de los directivos públicos generalmente tienen tres elementos: un sueldo base, un complemento ligado al puesto de trabajo y un complemento vinculado al rendimiento.

Dentro del proceso de modernización de las Administraciones, la introducción de la retribución por objetivos ha sido un elemento clave. Si en el sector privado hay una larga tradición de retribución por objetivos, su introducción en la Administración ha implicado un cambio de cultura, pues supone una mayor evaluación de los resultados y un mayor grado de responsabilidad.

La OCDE señala que la retribución por objetivos en la Administración tiene peculiaridades que no deben obviarse (OCDE, 2005). En primer lugar, de estudios efectuados en EEUU y en Reino Unido, se concluye que la retribución por objetivos en el Sector Público tiene un escaso valor de motivación frente a otros factores como son la satisfacción por el trabajo y las expectativas de carrera. Sin embargo, la retribución por objetivos tiene un gran valor como catalizador de cambios, ya que permite redefinir procedimientos, definir objetivos, clarificar funciones e favorecer el trabajo en equipo y las habilidades profesionales.

El mayor problema en la implantación de retribuciones por objetivos en los directivos públicos se encuentra en la dificultad de fijar dichos objetivos. En las organizaciones públicas que prestan servicios (Seguridad Social, prestaciones, Impuestos) resulta más sencillo cuantificar los objetivos que en la Administración " pura" (los servicios centrales de los Ministerios). Así, en el Informe Steering sobre el Senior Civil Service se considera que en la implantación de evaluación del desempeño, al utilizarse herramientas procedentes del sector privado, se han minusvalorado las habilidades propias y tradicionales del Civil Service, como son la capacidad de desenvolverse en un entorno político y el desarrollo de políticas públicas.

Según la OCDE, las principales tendencias en la retribución por objetivos de los directivos públicos son las siguientes:

1. Generalización de la retribución por objetivos entre los directivos públicos.

2. Inclusión de objetivos colectivos y no únicamente individuales.

3. Fomento de la delegación y la descentralización en las retribuciones por objetivos.

4. Inclusión de objetivos vinculados a habilidades profesionales y competencias y no únicamente a logros cuantitativos. 
5. Los sistemas de medición del rendimiento están menos estandarizados y menos definidos que hace diez años.

6. El porcentaje de retribución variable no es excesivamente relevante en comparación con el conjunto de las retribuciones.

La crisis económica puede hacer tambalearse todo el sistema de retribución por objetivos de los directivos públicos. En Reino Unido el nuevo Gobierno va a limitar la retribución por desempeño de manera que sólo la perciban el 25 \% de los directivos públicos que obtengan mejores evaluaciones y van a proceder a revisar todo el sistema de retribución por objetivos.

\section{CESE DE LOS DIRECTIVOS PÚBLICOS}

La relación entre los directivos públicos y la política se puede medir también en función del número de directivos públicos que cambian con la entrada de un nuevo Gobierno.

En las siguientes tablas, se muestra la incidencia del cambio de legislatura y de Gobierno en el mantenimiento o cese de los directivos públicos en los distintos países.

TABLA 5

Cambios de directivos públicos con el cambio de Gobierno

\begin{tabular}{|l|c|}
\hline \multicolumn{1}{|c|}{ País } & $\begin{array}{c}\text { ¿Existen niveles dentro de la función directiva que se cambian } \\
\text { con el cambio de Gobierno? }\end{array}$ \\
\hline EEUU & Sí \\
\hline Italia & Sí (Niveles 1,2,3) \\
\hline México & Sí \\
\hline Polonia & Sí (Nivel 1) \\
\hline Corea & Sí (Nivel 1) \\
\hline Francia & Sí (Nivel 1) \\
\hline Bélgica & Sí (Nivel 1) \\
\hline Reino Unido & No (salvo los Ministers' special advisors) \\
\hline Nueva Zelanda & No \\
\hline Dinamarca & No \\
\hline Suecia & No \\
\hline
\end{tabular}

Fuente: OCDE, 2007. 
TABLA 6

Porcentaje de directivos públicos que cambian de puesto con los cambios de Gobierno

\begin{tabular}{|c|c|c|c|c|c|c|c|c|c|c|c|c|}
\hline \multirow{2}{*}{ País } & \multicolumn{2}{|c|}{ Nivel 1} & \multicolumn{2}{|c|}{ Nivel 2} & \multicolumn{2}{|c|}{ Nivel 3} & \multicolumn{2}{|c|}{ Nivel 4} & \multicolumn{2}{|c|}{ Nivel 5} & \multicolumn{2}{|c|}{ Asesores } \\
\hline & A & B & A & B & $A$ & B & A & B & A & B & A & B \\
\hline EEUU & 6 & 100 & 6 & 100 & 6 & 100 & 6 & 100 & 6 & 100 & & \\
\hline México & 55 & 100 & 55 & 100 & 55 & 70 & 55 & 70 & 55 & 70 & 55 & 100 \\
\hline Italia & - & - & - & - & - & 100 & & 0* & & 0 & - & 100 \\
\hline Francia & - & - & $2-6$ & $1-5$ & $2-6$ & $1-5$ & - & - & - & - & - & - \\
\hline Bélgica & 0 & 0 & 0 & 0 & 0 & 0 & 0 & 0 & 0 & 0 & $0 / 100$ & $0 / 100$ \\
\hline Dinamarca & 0 & 0 & 0 & 0 & 0 & 0 & 0 & 0 & 0 & 0 & - & - \\
\hline
\end{tabular}

Fuente: OCDE, 2007.

* En la práctica en 2002 el 50\% de los directivos de nivel 4 cambiaron en Italia tras las elecciones.

A: Cambio a un Gobierno de igual color político.

B: Cambio a un Gobierno de distinto color político.

Estos datos son un indicador del grado de separación o injerencia entre política y dirección pública. Una mayor tasa de rotación es indicadora de un alto grado de participación política en la dirección política.

Para garantizar cierto grado de autonomía en la gestión, algunos países han introducido periodos fijos en la duración del mandato del directivo público. No obstante, en muchos países la permanencia en el puesto directivo está ligado al logro de objetivos. Con frecuencia, se diferencia entre el cese en el puesto directivo (que suele ser más discrecional o estar vinculado al desempeño) y la permanencia en la condición de "funcionario" sentido amplio o incluso en el estrato directivo. En muchas Administraciones se utiliza la figura del cambio de puesto más que el cese total del directivo público.

\section{EL DIRECTIVO PÚBLICO PROFESIONAL EN ESPAÑA}

\subsection{Régimen jurídico}

La Exposición de Motivos del Estatuto del Empleado Público considera que la nueva figura del directivo público profesional "está llamado a constituir en el futuro un factor decisivo de modernización administrativa, puesto que su gestión profesional se somete a criterios de eficacia y eficiencia, responsabilidad y control de resultados en función de los objetivos.

Esta ley no define al directivo público profesional como una clase de personal. Según el artículo 8.2 Los empleados públicos se clasifican en:

a) Funcionarios de carrera.

192 b) Funcionarios interinos. 
C) Personal laboral, ya sea fijo, por tiempo indefinido o temporal.

d) Personal eventual.

Por tanto, el personal directivo no es una clase de personal al margen de las enumeradas.

Dado el carácter básico del EBEP y la voluntad del legislador, expresada en la Exposición de Motivos de que "el régimen de función pública no puede configurarse hoy sobre la base de un sistema homogéneo que tenga como modelo único de referencia la Administración del Estado", el artículo 13, dedicado al personal directivo profesional, no efectúa una clara definición del mismo sino que considera que "es personal directivo el que desarrolla funciones directivas profesionales en las Administraciones Públicas, definidas como tales en las normas específicas de cada Administración."

El régimen jurídico del directivo público profesional vendrá recogido por tanto en las leyes de desarrollo del Estatuto. Sin embargo, sí que existen unos principios básicos en la regulación:

\section{- Reserva a funcionarios:}

El personal directivo puede ser funcionario o laboral (artículo 13.4) pero, y es uno de los elementos más importantes del EBEP, en todo caso el ejercicio de las funciones que impliquen la participación directa o indirecta en el ejercicio de las potestades públicas o en la salvaguardia de los intereses generales del Estado y de las Administraciones públicas corresponden exclusivamente a los funcionarios públicos, en los términos que en la ley de desarrollo de cada Administración se establezca (artículo 9.2).

- Su designación atenderá a principios de mérito y capacidad y a criterios de idoneidad, y se llevará a cabo mediante procedimientos que garanticen la publicidad y concurrencia (artículo 13.2).

- El personal directivo estará sujeto a evaluación con arreglo a los criterios de eficacia y eficiencia, responsabilidad por su gestión y control de resultados en relación con los objetivos que les hayan sido fijados.

- Sus condiciones de trabajo no son objeto de negociación.

En el ámbito estatal, la Ley 6/1997, de 14 de abril, de organización y funcionamiento de la Administración General del Estado diferencia en la organización central entre órganos superiores (Ministros y Secretarios de Estado) y órganos directivos.

Los órganos directivos son los siguientes:

a) Subsecretarios y Secretarios Generales.

b) Secretarios Generales Técnicos y Directores Generales.

c) Subdirectores Generales. 
Sin embargo, no todos tienen el mismo tratamiento. La LOFAGE concede un estatus distinto, más administrativo, a los Subdirectores Generales, considerados en la Exposición de Motivos, como los órganos en los que comienza el nivel directivo de la A.G.E y que, a diferencia de los anteriores, son nombrados por el Ministro o Secretario de Estado y no por Real Decreto.

En la Exposición de Motivos se señala que "como garantía de objetividad en el servicio a los intereses generales la Ley consagra el principio de profesionalización de la Administración General del Estado, en cuya virtud los Subsecretarios y Secretarios Generales Técnicos, en todo caso, y los Directores Generales, con carácter general, son altos cargos con responsabilidad directiva y habrán de nombrarse entre funcionarios para los que se exija titulación superior”. Los Secretarios Generales son órganos directivos pero su titular no tiene que tener la condición de funcionario de carrera del actual subgrupo A1." Además, el nombramiento se efectuará atendiendo a criterios de competencia profesional y experiencia.

De acuerdo con lo anterior, se podría clasificar los órganos directivos de la organización central de la AGE en los siguientes:

TABLA 7

Órganos directivos en la organización central de la LOFAGE

\begin{tabular}{|c|c|c|}
\hline Órgano & Nombramiento & Titular \\
\hline Subsecretario & Real Decreto & Funcionarios de carrera A1 \\
\hline Secretario General & Real Decreto & No hay limitaciones \\
\hline Director general & Real Decreto & $\begin{array}{c}\text { Funcionarios de carrera A1 } \\
\text { con posibilidad de } \\
\text { excepciones }\end{array}$ \\
\hline Secretario General Técnico & Real Decreto & Funcionarios de carrera A1 \\
\hline Subdirectores Generales & $\begin{array}{r}\text { Por el Ministro o Secretario } \\
\text { de Estado }\end{array}$ & Funcionarios de carrera A1 \\
\hline
\end{tabular}

El Tribunal Supremo ha consolidado una doctrina sobre la posibilidad del nombramiento de Directores Generales que no tengan la condición de funcionarios de carrera ${ }^{3}$. Los aspectos principales de dicha doctrina jurisprudencial son los siguientes:

1. La LOFAGE ha establecido como regla la cobertura de puestos de Director General por funcionarios de carrera de nivel superior.

3 Sentencia de 21 de marzo de 2002, dictada en el recurso 1060/2000, de 6 de marzo de 2007, dictada en el recurso 23/2006, sentencias de 21 de enero de 2009, dictadas en los recursos 238 y 237 de 2006 y la reciente sentencia de 3 de septiembre de 2010, dictada en el recurso 528/2008. 
2. De acuerdo con la ley, el Consejo de Ministros puede excluir que una determinada Dirección General sea servida por funcionarios de nivel superior.

3. Esta exclusión:

a. Tiene que venir contemplada precisamente en el Real Decreto de estructura del departamento.

b. Debe tener como causa las características específicas de las funciones atribuidas a la Dirección General.

i. El Consejo de Ministros tiene un cierto margen de discrecionalidad en la apreciación de qué tipo de características específicas permiten la cobertura por no funcionarios pero ello no impide el control jurisdiccional del acto.

ii. Deben basarse en hechos objetivos y concretos y no bastan consideraciones abstractas o juicios de valor genéricos.

4. La exclusión de la condición de cobertura de una Dirección General por funcionarios de carrera de nivel superior:

a. No exime del cumplimiento de los criterios de profesionalidad y experiencia

b. Permite que el Consejo de Ministros nombre para esa Dirección General a funcionarios de carrera o a personas que no tengan dicha condición.

La LOFAGE ha suscitado críticas precisamente por la apuesta por la profesionalización de los puestos directivos a través de la exigencia de la condición de funcionarios como regla. Desde una perspectiva diferente, en 2006, la Ley 28/2006, de Agencias estatales para la mejora de los servicios públicos introduce un régimen de personal directivo más cercano a los países con un sistema de puesto que al sistema de carrera. Esta norma intentaba introducir en España un sistema similar al inglés, permitiendo las entradas laterales (contratos de alta dirección) e implantando la posibilidad de selección por órganos especializados que proponen de manera motivada tres candidatos, como se ha analizado anteriormente, esta figura es un mecanismo para garantizar mayor transparencia y objetividad en los procesos de nombramientos. Los nombramientos se deben efectuar atendiendo a los criterios de competencia profesional y experiencia entre titulados superiores preferentemente funcionarios, y mediante procedimiento que garantice el mérito, la capacidad y la publicidad.

Con el desarrollo de la Ley, la mayor parte de las Agencia creadas mantienen la cobertura de los puestos directivos por personal funcionario como regla, si bien en muchos casos contemplan alguna excepción. En varias Agencias (AEVAL, AECID, 
Agencia de Seguridad Aérea, Agencia de Meteorología) se prevé la existencia de un órgano de selección que propone una terna de candidatos.

TABLA 8

Nombramiento del Personal Directivo de las Agencias Estatales

\begin{tabular}{|c|c|c|c|c|}
\hline Agencia & $\begin{array}{c}\text { Criterios } \\
\text { de selección }\end{array}$ & $\begin{array}{c}\text { Órgano } \\
\text { especializado } \\
\text { de selección }\end{array}$ & $\begin{array}{l}\text { Cobertura } \\
\text { general }\end{array}$ & Excepciones \\
\hline $\begin{array}{l}\text { Agencia Estatal } \\
\text { de evaluación de } \\
\text { políticas públicas } \\
\text { y calidad de los } \\
\text { servicios AEVAL } \\
\text { RD1418/2006 }\end{array}$ & $\begin{array}{l}\text { Criterios de } \\
\text { competencia y } \\
\text { experiencia } \\
\text { garantizando } \\
\text { publicidad, mérito y } \\
\text { capacidad }\end{array}$ & Posible & Funcionario & \begin{tabular}{|l|} 
Los directores de \\
división pueden \\
ser laborales \\
mediante \\
contrato de alta \\
dirección \\
\end{tabular} \\
\hline $\begin{array}{l}\text { Agencia Española } \\
\text { de Cooperación } \\
\text { Internacional } \\
\text { para el Desarrollo } \\
\text { RD1403/2007 } \\
\text { RD 822/2008 }\end{array}$ & $\begin{array}{l}\text { Criterios de } \\
\text { competencia } \\
\text { profesional, } \\
\text { idoneidad, } \\
\text { experiencia e igualdad } \\
\text { de género, } \\
\text { garantizando mérito, } \\
\text { la capacidad y la } \\
\text { publicidad }\end{array}$ & Sí & $\begin{array}{l}\text { Funcionarios } \\
\text { y laborales } \\
\text { mediante } \\
\text { contratos de } \\
\text { Alta } \\
\text { dirección }\end{array}$ & \\
\hline $\begin{array}{l}\text { Agencia BOE } \\
\text { RD 1495/2007 }\end{array}$ & $\begin{array}{l}\text { Criterios de } \\
\text { competencia y } \\
\text { experiencia } \\
\text { profesional }\end{array}$ & Sí & Funcionario & \\
\hline $\begin{array}{l}\text { CSIC } \\
\text { RD 1730/2007 }\end{array}$ & $\begin{array}{l}\text { Criterios de } \\
\text { competencia y } \\
\text { experiencia } \\
\text { garantizando } \\
\text { publicidad, mérito y } \\
\text { capacidad }\end{array}$ & & Funcionarios & $\begin{array}{l}\text { Coordinadores de } \\
\text { redes científicas, } \\
\text { que se cubrirán } \\
\text { con contratos } \\
\text { laborales de Alta } \\
\text { dirección } \\
\end{array}$ \\
\hline $\begin{array}{l}\text { Agencia Estatal } \\
\text { de Seguridad } \\
\text { Aérea } \\
\text { RD } 184 / 2008 \text { y RD } \\
1615 / 2008\end{array}$ & $\begin{array}{l}\text { Criterios de } \\
\text { competencia y } \\
\text { experiencia } \\
\text { garantizando } \\
\text { publicidad, mérito y } \\
\text { capacidad } \\
\end{array}$ & Posible & Funcionarios & $\begin{array}{l}\text { El jefe de la } \\
\text { división de } \\
\text { control de } \\
\text { operaciones en } \\
\text { vuelo }\end{array}$ \\
\hline $\begin{array}{l}\text { Agencia Estatal } \\
\text { Antidopaje } \\
\text { RD 185/2008 }\end{array}$ & $\begin{array}{l}\text { Criterios de } \\
\text { competencia } \\
\text { profesional y } \\
\text { experiencia mediante } \\
\text { procedimiento que } \\
\text { garantice la publicidad } \\
\text { y la concurrencia, } \\
\text { mérito y capacidad }\end{array}$ & & Laboral & \\
\hline $\begin{array}{l}\text { Agencia Estatal } \\
\text { de Meteorología } \\
\text { RD 186/2008 }\end{array}$ & $\begin{array}{l}\text { Criterios de } \\
\text { competencia y } \\
\text { experiencia } \\
\text { garantizando } \\
\text { publicidad, mérito y } \\
\text { capacidad }\end{array}$ & Posible & Funcionarios & \\
\hline
\end{tabular}




\subsection{Radiografía de los directivos públicos profesionales en la AGE}

Respecto al número de directivos públicos que hay en la Administración General del Estado, la propia indeterminación del concepto dificulta su cuantificación. Habría que incluir en dicha noción a los Subsecretarios, Directores Generales y Subdirectores Generales. Se podría discutir si los Secretarios Generales deben tener la consideración de directivos públicos, pero, la LOFAGE así los califica. Asimismo, dependiendo de las funciones algunos coordinadores de área, subdirectores adjuntos y jefes de área, con responsabilidades de gestión, podrían estar incluidos en el concepto. Por la misma razón, órganos staff de asesoramiento como vocales asesores no tendrían tal condición, si bien es cierto que existen numerosos ejemplos de vocales asesores que ejercen funciones directivas y cuentan con una estructura jerárquica subordinada.

Tras la aprobación del Real Decreto 1366/2010, de 29 de octubre, por el que se aprueba la estructura orgánica básica de los departamentos ministeriales, actualmente existen, en la estructura central de los departamentos ministeriales, los siguientes órganos directivos con rango igual o superior a dirección general:

TABLA 9

Número de altos cargos

\begin{tabular}{|l|c|}
\hline Subsecretarías & 15 \\
\hline Secretarías generales y otros órganos con rango de subsecretaría & 20 \\
\hline Secretarías Generales Técnicas & 15 \\
\hline Direcciones Generales & 116 \\
\hline
\end{tabular}

TABLA 10

Número de niveles 30, 29, 28

\begin{tabular}{|l|c|}
\hline Niveles 30 & 2.177 \\
\hline Niveles 29 & 1.975 \\
\hline Niveles 28 & 6.458 \\
\hline
\end{tabular}

Además, de acuerdo con los datos del Registro Central de Personal, a enero de 2010 había 2.177 niveles 30 en la A.G.E. y 1.975 niveles 29. En los niveles predirectivos, había 6.458 niveles 28 .

En el siguiente gráfico se muestra la proporción entre mujeres y hombres y la distribución por departamentos ministeriales de los niveles 30, 29 y 28. 
TABLA 11

Proporción entre mujeres y hombres

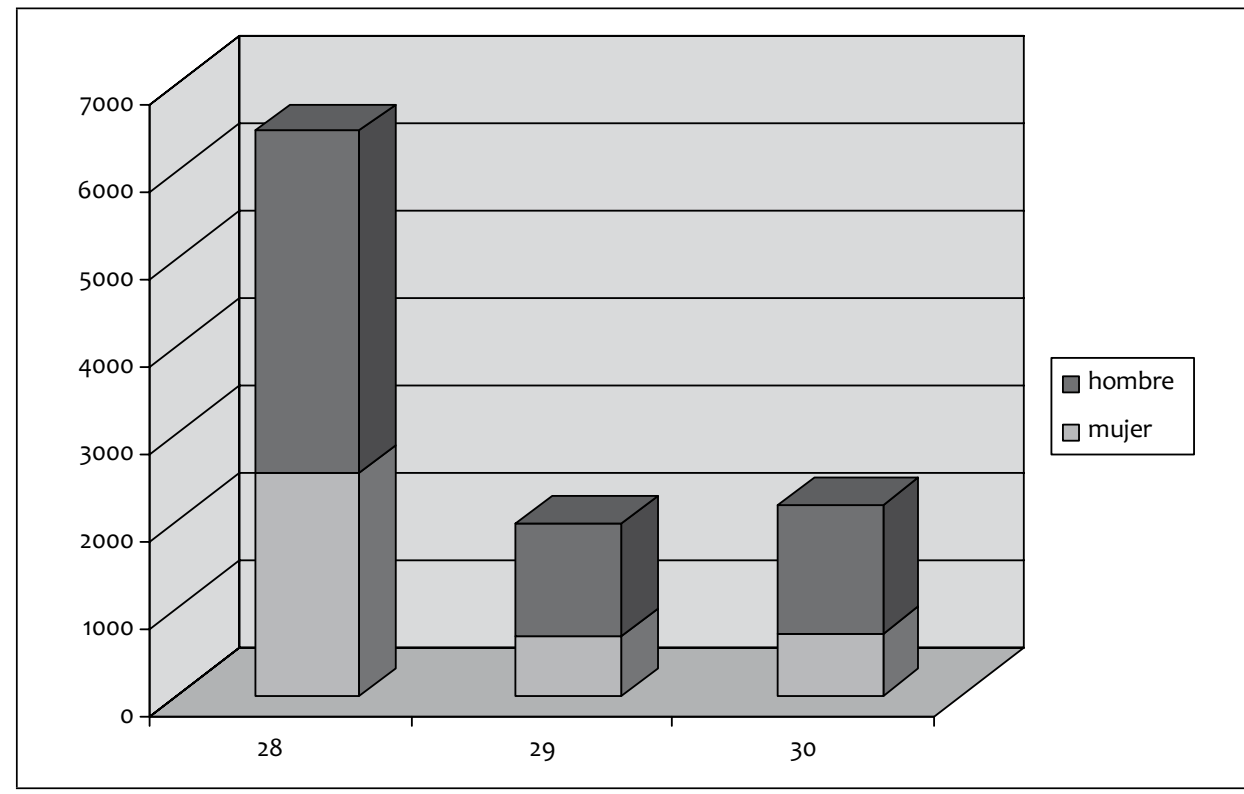

Fuente: RCP boletín estadístico enero 2010.

De acuerdo con la tabla, continúa existiendo una mayor presencia masculina en los puestos directivos y predirectivos de la Administración. Dicha tendencia probablemente irá disminuyendo con el tiempo por la entrada mayoritaria de mujeres en los Cuerpos Superiores. No obstante, las dificultades de conciliación de la vida profesional y laboral y los horarios prolongados, pueden hacer que estas diferencias continúen.

En cuanto a la tasa de rotación tras los cambios de Gobierno, no existen datos disponibles. El cambio de Gobierno de distinto color político suele implicar el cambio de Directores Generales y demás altos cargos. En caso de cambio de Gobierno pero no de partido político, se producen variaciones menores. No obstante, en ocasiones, los cambios de Ministro o Secretario de Estado, incluso dentro mismo partido, pueden implicar cambios en cadena en los meses sucesivos incluyendo los puestos de Subdirector General. La falta de datos al respecto dificulta medir este indicador de profesionalidad en la Administración.

Respecto a las retribuciones, en el siguiente cuadro se incluyen sueldo, complemento de destino y específico de acuerdo con el proyecto de ley de Presupuestos Generales del Estado para 2011. No se incluye el complemento de productividad cuya cuantía depende, en gran medida, de la dotación presupuestaria del departamento ministerial. 


\begin{tabular}{|c|c|}
\hline Puesto & Retribuciones \\
\hline Subsecretario & $63.704,89 €$ \\
\hline Director General & $54.707,69 €$ \\
\hline Subdirector General * & $52.572,24 €$ \\
\hline Subdirector General Adjunto* & $46.469,22 €$ \\
\hline
\end{tabular}

* Retribuciones medias.

Con el objeto de efectuar un somero diagnóstico de la situación actual de los directivos públicos en la $\mathrm{AGE}$, se ha efectuado un estudio entre 25 directivos públicos y privados $^{4}$.

Las conclusiones más destacables son las siguientes:

1. Competencias directivas: Los directivos públicos consideran que las competencias de un directivo más relevantes son la capacidad de motivación, la amplitud y profundidad de conocimientos y la capacidad de planificación. Mientras que los directivos empresariales valoran la capacidad de liderazgo y las competencias de comunicación y organización.

Llama la atención que los empresarios valoran especialmente las habilidades profesionales, mientras que en la Administración los conocimientos técnicos continúan teniendo un papel destacado, a pesar de que el directivo público tiene, o debería tener, una vocación generalista.

2. Comparación entre los directivos públicos y los directivos privados: Ambos colectivos consideran que los directivos públicos en comparación con los directivos del sector privado tienen un mayor conocimiento general de la Administración y una mayor vocación de servicio público. En cambio, ambos colectivos atribuyen a los directivos del sector privado una mayor eficacia.

3. Reserva a funcionarios: Las mayores diferencias se observan en el tratamiento de las entradas laterales. Los directivos públicos consideran mayoritariamente que sólo los funcionarios de carrera deberían ser directivos públicos, mientras que los directivos del sector privado no están de acuerdo con esta reserva.

No obstante, ambos colectivos coinciden en que en la selección del personal no funcionario no deben tenerse en cuenta las afinidades políticas y en que dicha selec-

4 La muestra no es elevada en cuanto número pero sí representativa en su composición. Los participantes en el estudio, con carácter anónimo, han sido funcionarios superiores que ocupan o han ocupado puestos de Subsecretarios, Directores Generales y Subdirectores Generales y que pertenecen a los Cuerpos de Abogados del Estado, Técnicos Comerciales y Economistas del Estado, Inspectores de Hacienda, Administradores Civiles del Estado, Inspectores de Trabajo y Seguridad Social, Técnicos de la Seguridad Social, Interventores de Hacienda. Los participantes del sector privado ocupan puestos directivos en empresas nacionales e internacionales. 
ción debería consistir en una valoración objetiva de los méritos profesionales. La selección por órganos especializados que propongan una terna de candidatos, quizá por ser más ajena a nuestra tradición, no recibe un apoyo entusiasta por ninguno de ambos colectivos.

4. Trasvase de directivos públicos al sector privado: Los bajos niveles retributivos y la falta de una verdadera carrera administrativa son las causas, según los directivos públicos, del trasvase de directivos públicos al sector privado.

5. Del sistema de oposiciones para la selección de funcionarios de Cuerpos Superiores ambos colectivos destacan, como elementos positivos, la garantía de la igualdad de oportunidades y que frena la politización de la Administración. Sin embargo, los directivos del sector privado son más críticos con su desarrollo, apoyando, muchos de ellos, la introducción de técnicas de selección del sector privado, lo que mayoritariamente es desaconsejado por los directivos públicos.

6. Acceso a la función directiva: Mayoritariamente los encuestados ${ }^{5}$ consideran que pertenecer al subgrupo A1 debe ser una condición necesaria pero no suficiente para acceder a la función directiva y que en el acceso a dicha función directiva no debe tenerse en cuenta la afinidad política. En la práctica, señalan que en el nombramiento se tienen en cuenta tanto la pertenencia a un Cuerpo determinado como la afinidad política, si bien esta respuesta habría que matizarla pues no se diferenció, al enunciarla, entre el nombramiento de directivos públicos que tienen la condición de Altos Cargos, y por tanto, un carácter más político (Subsecretarios, Directores Generales) y directivos públicos técnicos (Subdirectores Generales).

7. Régimen del directivo público: los encuestados del sector público consideran mayoritariamente que el nombramiento y cese de los directivos públicos debe ser libre, sin que haya un consenso sobre la existencia de periodos mínimos de permanencia. Mayoritariamente apoyan la existencia de una garantía retributiva temporal, que no permanente, tras el cese.

Si hoy se volviera a efectuar el estudio de la OCDE sobre la función directiva, podríamos aventurar que España continuaría en un posición no muy elevada teniendo en cuenta varios indicadores:

1. Continúa sin existir un colectivo directivo profesional diferenciado. De hecho, la regulación es tan amplia que deja muchas cuestiones abiertas, incluyendo la propia definición de directivo público.

2. No hay una regulación detallada de los mecanismos formales o informales para la selección de los directivos públicos y no existe en líneas generales una determinación previa de las competencias requeridas.

5 Esta pregunta únicamente se planteó a los directivos públicos. 
3. No se puede calcular la edad media de acceso a la función directiva puesto que no hay claridad respecto a qué debe considerarse función directiva. La OCDF incluye un indicador en función de la edad de acceso a la función directiva.

4. Y, como aspecto más importante, no se ha desarrollado el estatuto normativo propio de la función directiva.

\section{CONCLUSIONES Y RETOS DE LA REGULACIÓN DEL ESTATUTO DEL DIRECTIVO PÚBLICO PROFESIONAL}

La figura del directivo público es un elemento básico en la organización de la Administración, que, hasta la fecha, no está concretado. Su regulación debe efectuarse partiendo del sistema constitucional e institucional de España y dada su importancia, cuanto mayor sea el consenso obtenido en su desarrollo, mejor. Como elemento previo, debería existir un debate sobre el modelo de Administración que se pretende y sobre los siguientes puntos:

1. Definición de directivo público: La regulación tendría que comenzar por definir qué se entiende por directivo público, concretando cuáles son las funciones directivas dentro de la Administración. Ello exige un ejercicio previo de determinación del ámbito de actuación de la propia Administración.

2. Carácter político o administrativo: Sería preciso preguntarse previamente cómo es el modelo hacia el que se quiere caminar y qué tipo de perfil se busca en los directivos públicos. Hemos visto en este artículo que son igualmente válidos nombramientos políticamente neutrales, como en Reino Unido o nombramientos de carácter político, siempre que exista una gran transparencia y que haya mecanismos efectivos de control al Gobierno, como ocurre en EEUU. Lo importante es el conjunto de normas, costumbres y prácticas que garantizan el equilibrio del sistema y que evitan el abuso. El nombramiento de los directivos públicos es una pieza clave del engranaje constitucional y administrativo y es fiel reflejo del mismo. Por ello, sería conveniente lograr un consenso, lo más amplio posible, sobre los puestos directivos que deben tener un carácter político o político-administrativo y cuáles deben ser técnicos. En este aspecto, la OCDE recomienda precaución y tender hacia un equilibrio lejos de posiciones maximalistas. Un exceso de politización puede suponer la utilización de la Administración para fines partidistas. Por el contrario, normas demasiado rígidas respecto a la neutralidad, pueden conllevar el surgimiento de una para-administración a través de los asesores políticos.

3. Funcionarios o laborales: Es necesario determinar qué puestos deben estar reservados a funcionarios y en que ámbitos cabría la existencia de contratos de alta dirección. ¿Por qué se establece en el Estatuto Básico del Empleado Público una reserva a favor de los funcionarios? En primer lugar porque la inamovilidad en la condi- 
ción de funcionario de carrera es una garantía de mayor neutralidad. En segundo lugar, porque asegura el conocimiento de la cultura administrativa y de las especiales normas de gestión que en la Administración española rigen. Cualquier regulación en la materia debe tener en cuenta ambos elementos.

4. Selección: Respecto a la selección, en el caso de puestos de directivos públicos de contenido político, debe haber un gran margen de discrecionalidad, pues prima la confianza.

Respecto a los directivos técnicos, deben arbitrarse mecanismos que garanticen la selección de los mejores candidatos:

a) En el caso de puestos reservados a funcionarios, existen varias posibilidades: La primera es que se determinen unas condiciones previas para que los funcionarios del subgrupo A1 puedan tener la condición de "elegibles". Estas condiciones podrían estar vinculadas a la experiencia en puestos predirectivos, la pertenencia a un Cuerpo, antigüedad, conocimiento de idiomas, etc. También podría considerarse la implantanción de una "habilitación nacional". Otra opción, es en cada plaza se regulen los requisitos previos (antigüedad, experiencia en determinados ámbitos...). Estos requisitos previos servirían de filtro y podría haber mayor margen a la discrecionalidad en el nombramiento, pues ya se garantiza cierto nivel de profesionalidad.

Otra solución es establecer órganos especializados que efectúen la preselección y que planteen una terna al órgano que nombra.

Actualmente, los Cuerpos sirven de mecanismo informal de preselección de candidatos idóneos. No hay que desdeñar este papel, pues como ha señalado la OCDE en la regulación de los directivos importa no sólo la ley sino las prácticas y normas no escritas.

b) Respecto a la selección de no funcionarios, la OCDE y el Banco Mundial insisten en que la transparencia es el elemento más importante para evitar abusos y para garantizar la responsabilidad de los gobernantes por sus nombramientos. La definición previa de las competencias propias de cada puesto permitirá una búsqueda de los mejores candidatos. De nuevo, lo esencial es determinar previamente si los puestos deben exigir una confianza política o ser técnicos para, en consecuencia, medir el grado de intervención política en el nombramiento. Este es un debate que afecta a la sociedad, pues influye en la configuración de la actuación pública.

5. Cese: Tan importante como el nombramiento es la regulación del cese. Ambos deben estar en sintonía. Si el nombramiento ha sido discrecional, el cese también debe tener esta consideración. Si no lo ha sido, se pueden contemplar periodos mínimos de prestación sujetos a evaluación del desempeño.

a) En el caso de funcionarios, deben regularse las garantías retributivas y profe-
202 sionales de los directivos cesados. El desarrollo de la carrera horizontal resulta impres- 
cindible en este punto, de manera que el desempeño de un puesto directivo durante un tiempo prolongado suponga una mayor garantía retributiva que la consolidación del grado actual. En este sentido, podrían introducirse mecanismos para dotar al sistema de mayores estabilizadores mediante la introducción de una garantía temporal ${ }^{6}$ de mantenimiento de retribuciones en caso de cese para funcionarios en activo.

b) En el caso de personal laboral, convendría abordar el tema de las indemnizaciones por cese, ya que el Estatuto configura los contratos de Alta Dirección como la modalidad correspondiente a los directivos no funcionarios.

6. Retribuciones: Respecto a las condiciones retributivas, la actual coyuntura económica exige gran contención. No obstante, hay que tener en cuenta que sin unas retribuciones atractivas no se garantiza la selección de los mejores profesionales, ni su permanencia en la Administración. También, siguiendo el modelo inglés, habría que huir de diferencias retributivas entre personal funcionario y laboral. De nuevo la transparencia es la mejor garantía frente a los posibles abusos. Como de los distintos informes del Parlamento inglés se ha visto, la contratación de personal laboral ajeno supone en muchas ocasiones un sobrecoste. En las actuales circunstancias, hay que sopesar las ventajas de proceder a dichas contrataciones frente al recurso al mercado interno.

Por otro lado, la vinculación de las retribuciones al rendimiento y al desempeño debe tener en cuenta las peculiaridades de la gestión pública. No ha sido el objeto de este artículo, pero las diferencias existentes en retribuciones de puestos directivos entre Administraciones y dentro de la misma AGE no tienen una justificación, en la mayor parte de los casos, objetiva, sino que son consecuencia de las diferentes disponibilidades presupuestarias.

De todo lo analizado en este artículo, se deduce la importancia de la cuestión de los directivos públicos y la dificultad de su regulación. No hay soluciones universales que puedan ser aplicables a todos los países. ¿Por qué? Porque la figura del directivo público es consecuencia del sistema constitucional y administrativo de cada país. Porque la figura del directivo público es definitoria de la relación entre política y administración. Porque en la figura del directivo público cuentan no sólo las regulaciones expresas sino, y con un papel estelar, las prácticas y costumbres administrativas que actúan como normas no escritas. Porque la función pública es un sistema, un conjunto de normas, acuerdos, principios y una cultura administrativa, cuya cúspide, la función directiva, debe guardar armonía con el resto del conjunto. Por ello, la regulación del estatuto del directivo público no es una más entre las distintas cuestiones de empleo público, sino la clave de bóveda para la configuración de la Administración.

No hay consenso en la regulación del directivo público porque no hay consenso en la definición de lo que debe ser la Administración.

6 Por ejemplo, tres meses como ocurre con los titulares de puestos suprimidos. 
Para finalizar, las conclusiones del informe sobre el Servicio Público que aprobó la Cámara de los Lores en 1997:

"Se ha calificado al "Civil Service" inglés como la envidia del mundo. En otro punto de este informe destacábamos sus rasgos característicos: ausencia de partidismo, integridad, imparcialidad, objetividad, lealtad y prevención frente a la corrupción. En los últimos treinta años ha habido una reducción sustancial de las operaciones que se llevan a cabo dentro del modelo de Civil Service clásico y de acuerdo con sus principios y ética. Algunas de estas operaciones se realizan actualmente total o parcialmente por compañías del sector privado cuya primera responsabilidad es con los accionistas. Puede ser cierto que se pueda producir un servicio mejor a un precio menor pero la cuestión de si un servicio debe prestarse por el Civil Service clásico, o por organismos públicos a los que se otorgan poderes, o por el sector privado no es únicamente una cuestión de management y de eficiencia, es una cuestión de política pública.

El Comité considera que no es en absoluto sencillo trazar una línea que delimite un mínimo público irreductible. Para ello, sería preciso definir cual es el campo de actuación propio del Gobierno, un debate que ha enfrentado a los gobernantes y a los gobernados a lo largo de siglos. Sin embargo, en una democracia madura esto debe ser objeto de un debate abierto y público, y una materia en la que el Parlamento debe tomarse un interés activo. La cuestión de lo que es "la esencia del Gobierno" es un tema que afecta tanto a los gobernantes como a los gobernados. El Comité considera deseable que el Gobierno defina su propio concepto de aquellas funciones irreductibles que deben llevarse a cabo por el Civil Service clásico, al menos para eliminar el miedo a que haya una erosión del Civil Service en el futuro."

\section{BIBLIOGRAFÍA}

House of Lords, (1998) Public Service Report, Publications on the internet Public Service Committee Reports.

OCDE, (2003) Managing Senior Management: Senior Civil Service reform in OECD Member Countries, OECD Publishing, Paris.

Banco Mundial, (2005) Senior Public Service: high performing managers of government.

OCDE, (2005) Performance-related Pay Policies for Government Employees, OECD Publishing, Paris.

Coordinador, Miguel Sánchez Morón, (2007), La función pública directiva en Francia, Italia y España, INAP.

Matheson, A. et al (2007) "Study on the Political Involvement in Senior Staffing Decisions ando on the Delineation of Responsabilities Between Ministers and Senior Civil Servants" OCDE Working Papers on Public Governance 2007/6 OECD Publishing. 
Silicani, (2007), Livre Blanc sur l’Avenir de la Fonction Publique, Ministère du Buget et des comptes publics et de la fonction publique, Paris.

Report of the Steering Group (2008) Senior Civil Service Workforce and Reward Strategy.

OCDE (2008), The State of the Public Service, OECD Publishing, Paris.

House Of Commons, (2010) Public Administration Committee, Seventh Report, Outsiders and insiders: External Appointments to the Senior Civil Service, Public Administration Committee Publications.

Director: Jordi Sevilla, (2010) La reforma de la Administración General del Estado, LID, Madrid.

Ministerio de la Presidencia, (2010), El empleo público en España, Secretaría General Técnica, Madrid.

Recibido: 23 de noviembre de 2010

Aceptado: 25 de noviembre de 2010 
